\title{
Strangulated giant transdiaphragmatic hernia: A rare complication of coronary artery bypass grafting with the right gastroepiploic artery
}

\author{
Majid Ansari, MD, Philippe Eucher, MD, and Louis De Canniere, Yvoir, Belgium
}

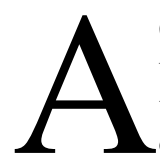

65-year-old man with coronary artery disease had undergone coronary artery bypass grafting (CABG) with one saphenous graft to the interventricular anterition of $15 \%$, he underwent a second uneventful CABG in 1998

From the Catholic University of Louvain (UCL), Mont-Godinne University Hospital, Yvoir, Belgium.

Received for publication March 14, 2001; accepted for publication May 21, 2001.

Address for reprints: Majid Ansari, MD, Catholic University of Louvain (UCL), Mont-Godinne University Hospital, Yvoir B-5530, Belgium (E-mail ansm39@yahoo.fr).

J Thorac Cardiovasc Surg 2002;123:358-9

Copyright $\odot 2002$ by The American Association for Thoracic Surgery

$0022-5223 / 2002 \$ 35.00+0 \quad \mathbf{1 2 / 5 4 / 1 1 8 0 3 8}$

doi: $10.1067 / \mathrm{mtc} .2002 .118038$ with left and right internal thoracic arteries and the right gastroepiploic artery to the interventricular anterior artery, circumflex, and interventricular posterior artery, respectively.

In June 1999, after sudden paraumbilical and acute epigastric pain followed by nausea, emesis, and obstipation, the patient was admitted to a gastroenterology unit. He was discharged on the second day after making good progress with medical treatment. The diagnosis was an organoaxial gastric valveless probably made possible by an epigastric hernia and the rise of the right hemidiaphragmatic dome (palsy of right phrenic nerve).

One year later in June 2000 the patient was admitted to the emergency room for paraumbilical and acute epigastric pain with nausea and vomiting. He also had dyspnea in the supine position. A repeat electrocardiogram did not show transient myocardial ischemia. A plain radiograph of the chest revealed the gas-filled loops of intestine with multiple fluid levels in the right base of the thorax. A computed tomographic scan showed a voluminous right transdiaphragmatic hernia with encroachment of nearly all the small intestines, omentum, and transverse colon into the right side of the thorax. The computed tomographic scan of the thorax in 


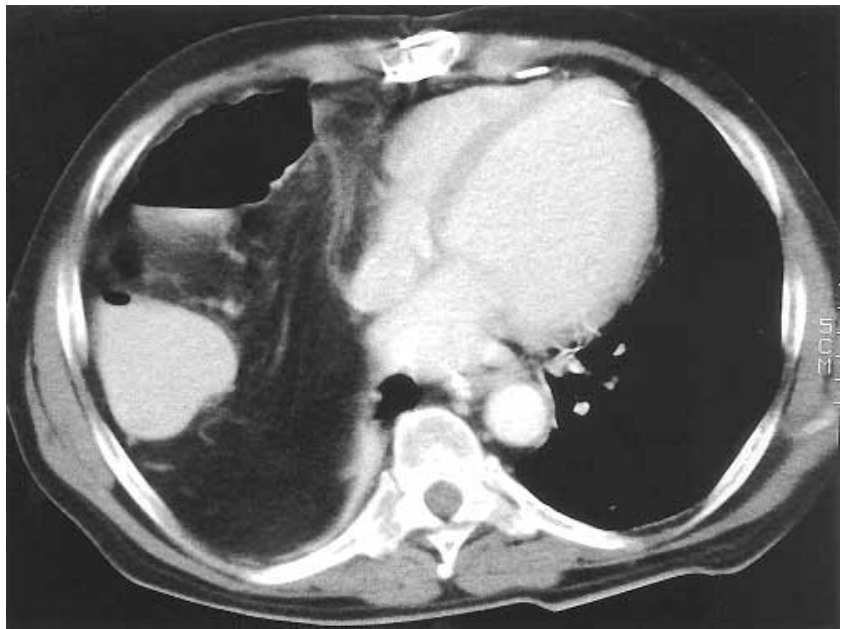

Figure 1. A computed tomographic scan of the thorax in June 1999 showed a voluminous right transdiaphragmatic hernia.

June 2000 showed the same image as the scan in June 1999 (Figures 1 and 2). This was compatible with a diagnosis of strangulated intrathoracic hernia. In view of these symptoms, an operation was advised.

The patient underwent a right thoracophrenolaparotomy, which confirmed the diagnosis associated with milky pleural effusion. Compression of the right lung in the top of the thorax was severe. A chronic stenosis of the small intestine at the level of the diaphragmatic defect was visible but did not require segmental resection.

After reduction of the hernia into the abdominal cavity, the diaphragmatic defect was repaired with a nonresorbable surgical patch and the interposition of a second patch between the retracted sides of the two rectus abdominalis muscles. Although the ventricular ejection fraction was $15 \%$, the postoperative recovery was uneventful and the collapsed lung reexpanded nicely. The patient has been free of symptoms since the operation.

\section{Comment}

The right gastroepiploic artery was first used as a conduit for CABG in 1973 and has become increasingly popular as an alternative $\mathrm{CABG}$ conduit for coronary revascularization. Many stud-

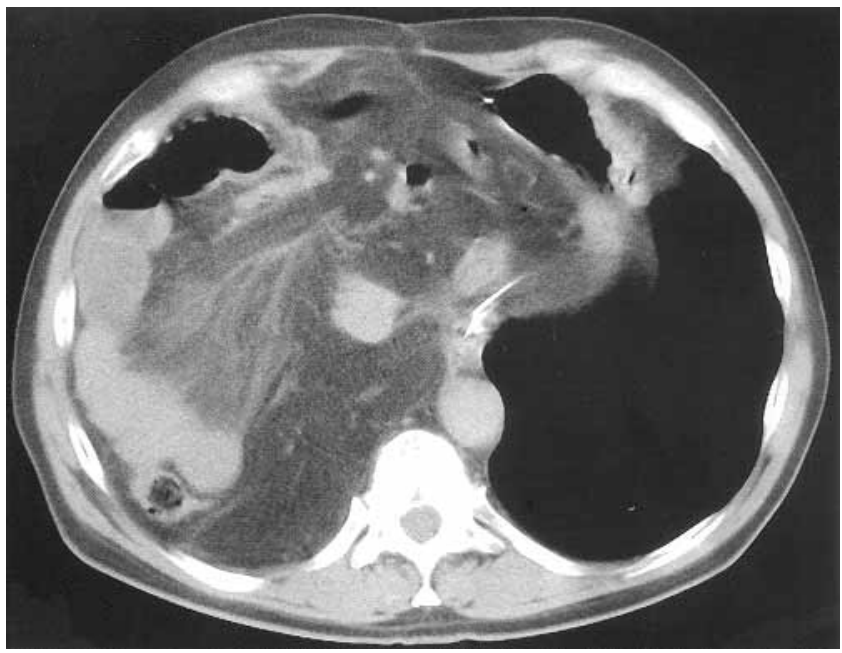

Figure 2. A computed tomographic scan of the thorax in June 2000.

ies have shown it to be a safe and effective conduit, and the complications are few.

In the absence of risk factors such as chronic cough, pregnancy, obesity, blunt trauma, and ascites, the most likely cause of transdiaphragmatic hernia in this patient was an overly large window for the gastroepiploic artery pedicle.

\section{References}

1. Manetta F, Moons DWO, Bennett EV, Edwards NM. Intrapericardial herniation of the stomach after use of right gastroepiploic artery for coronary artery bypass grafting. J Thorac Cardiovasc Surg. 1998;115:479-80.

2. McCaig J, Varghese JC, Rees MR. Transdiaphragmatic gastric herniation: a rare complication of CABG using the right gastroepiploic artery. Clin Radiol. 1996:51:143-5.

3. Verhofste MA, Tam SK. Diaphragmatic hernia after right gastroepiploic artery coronary artery bypass grafting. Ann Thorac Surg. 1995; 60:458-9.

4. Pasic M, Carrel T, Von Segesser L, Turina M. Postoperative diaphragmatic hernia after use of the right gastroepiploic artery for coronary artery bypass grafting [letter]. J Thorac Cardiovasc Surg. 1994;108: 189-91.

5. Caes FL, Francois B, Van Nooten GJ. Transdiaphragmatic herniation of the stomach after right gastroepiploic artery grafting. $J$ Thorac Cardiovasc Surg. 1994;108:191-3. 